\title{
Control of an Anthropomorphic Manipulator using LuGre Friction Model - Design and Experimental Validation
}

\author{
Khurram Ali ${ }^{1}$ - Adeel Mehmood ${ }^{1}$ - Israr Muhammad ${ }^{1}$ - Sohail Razzaq ${ }^{2}$ - Jamshed Iqbal 3,* \\ ${ }^{1}$ COMSATS University Islamabad, Department of Electrical and Computer Engineering, Islamabad, Pakistan \\ ${ }^{2}$ COMSATS University Islamabad, Department of Electrical and Computer Engineering, Abbottabad, Pakistan \\ ${ }^{3}$ University of Hull, Faculty of Science and Engineering, Department of Computer Science and Technology, Hull, UK
}

\begin{abstract}
Automation technology has been extensively recognized as an emerging field in various industrial applications. Recent breakthrough in flexible automation is primarily due to deployment of robotic arms or manipulators. Autonomy in these manipulators is essentially linked with the advancements in non-linear control systems. The objective of this research is to propose a robust control algorithm for a five degree of freedom (DOF) robotic arm to achieve superior performance and reliability in the presence of friction. A friction compensation-based non-linear control has been proposed and realized for the robotic manipulator. The dynamic model of the robot has been derived by considering the dynamic friction model. The proposed three-state model is validated for all the joints of the manipulator. The integral sliding mode control (ISMC) methodology has been designed; the trajectories of system every time begin from the sliding surface and it eliminates the reaching phase with assistance of integral term in the sliding surface manifold. The designed control law has been first simulated in Matlab/Simulink environment to characterize the control performance in terms of tracking of various trajectories. The results confirm the effectiveness of the proposed control law with model-based friction compensation. The transient parameters like settling and peak time have improvement as well have better results with friction than without considering the friction. The proposed control law is then realized on an in-house developed autonomous articulated robotic rducational platform (AUTAREP) and NI myRIO hardware interfaced with LabVIEW. Experimental results also witnessed the trajectory tracking by the robotic platform.
\end{abstract}

Keywords: robotic manipulator, lugre friction model, sliding mode control
Highlights
- A dynamic model of robot manipulator is presented in this work by considering the friction between the joints.
- Dynamic LuGre model is used for friction which reflects the real friction phenomenon by considering stick-slip motion and stribeck effect.
- Sliding mode control technique is used to design the control law using Lyapunov stability theorem.
- Controller performance is evaluated with and without friction compensation in Matlab.
- Proposed controller is also tested on experimental test bench using NI myRio 1900 and AUTAREP robot system.

\section{INTRODUCTION}

Robotic arms are playing a pivotal role in today's industrial world [1]. The industrial automation methods are majorally affected by the development in the field of robotics. Robotic arms are basically the mechanical replication of the human body arm. Research shows that they can outperform the humans in terms of strength, precision, speed and repeatability, thus, they can save time with improved performance [2]. Owing to these concrete reasons, robotic arms have acquired an invaluable place in industry [3]. To achieve high precision in robotic manipulators, friction in joints is the major limitation [4]. A manipulator, being inherently non-linear in nature, can demonstrate steady-state error and limit cycles and hence may suffer from degraded performance [5]. It affects both dynamic and static performances and can results in instability due to coupling effects. Henceforth, joint friction compensation in robot has been one of the major research problem in control design throughout the years. Friction is one of the main reasons of unwanted effects and system performance degradation [6]. Friction is a force which mostly occurs in moving systems exhibiting a complex phenomenon and can be divided into two types. The first type is known as static friction $F_{S}$ which is often defined for the bodies at rest. The other type is known as dynamic friction which occurs when one body is moving with respect to some other body in contact. It is further divided into three components. One component is recognized as sliding friction and others are rolling and pivot friction [7].

Static friction models like Karnopp model are difficult to implement while simulating the dynamic systems [8]. The dynamic friction models established so far cover majority of non-linear phenomena and they exhibit continuous behavior when the velocity is zero. These characteristics make the dynamic models more useful and convenient for software simulations and analysis of control algorithms. It is known that some of the foremost restrictions to realize 
admirable breakthrough in mechanical frameworks is the presence of friction, which is a non-linear phenomenon and hard to depict analytically [9]. Friction should be taken into account at an early stage throughout the system design by reducing it at probable minimum limit through careful design. Moreover, research shows that most of the dynamic models developed so far are incapable to capture the real friction phenomenon experienced by surfaces in contact [10]. The LuGre friction model is used in the current research since it describes important friction behaviour and characteristics such as stick-slip motion and stribeck effect etc. [11]. While demonstrating advantages of friction modelling, the LuGre friction model can result in numerically stiff and tough system dynamics. Moreover, the LuGre model performs like a linear spring pair when it is linearized for small motions. For a control engineer, it is suitable to analyse the impact of friction on the feedback system in order to design a control law that reduces the effect of friction.

In robotics, non-linear, centralized trajectory tracking refers to the input torque computation which guarantees precise tracking of reference trajectory. The research community has suggested numerous control approaches varying from simple linear feedback control to sophisticated algorithms. Sliding mode control (SMC) is one of the robust non-linear control techniques based on principle of the variable structure control theory. The key features of SMC include system robustness [12] and its stability against matched uncertainties [13]. The dynamics of a robotic manipulator having multi-DOF is complicated and highly non-linear [14]. The position of a single joint and its two higher derivatives have a strong impact on all joints of robotic manipulator. Moreover, gravity, external forces, modelling uncertainties, and friction can impact the robot motion. The state-of-the-art research works have been reported in the literature on robotic manipulator that uses friction models instead of a disturbance. An adaptive robust control (ARC) algorithm has been proposed for an electric cylinder with the LuGre friction model in [15] and the Lyapunov approach has been suggested for system stability and ARC handles external disturbances. In [16], to lessen the impact of estimation errors the robust sliding mode controller with an adaptive block compensation controller is proposed. The inverted pendulum and planar multi-joint robot with friction model are used to validate the controller. Authors in [17] used adaptive ISMC with time-delay estimation.

In this paper, an ISMC for anthropomorphic manipulator based on modified LuGre model with friction compensation is proposed. The following is a brief description of the main contribution:

- Mathematical model of AUTAREP robotic manipulator is centered on a five DOF has been derived by considering the kinematics and dynamics of the robot manipulator, as well as the LuGre friction model.

- Robust controller has been designed to compensate the dynamic friction behaviors and drive the position and speed to track the desired trajectories. The integral sliding mode control (ISMC) law, which is based on the Lyapunov function, is used to compensate for the system's parametric and load torque uncertainties.

- The proposed control law is then implemented on a custom developed platform using LabVIEW interface with NI myRIO hardware having motors driving circuits.

This article is organised as follows; Section 1 derives the mathematical model of a single joint along with LuGre friction model. In Section 2, SMC based control law is designed. After the control design, in section 3, outcomes of control design have been analysed and experimental results are discussed. Section 4 concludes the article.

\section{MATHEMATICAL MODELLING}

A robotic manipulator usually consists of servo motors, optical encoders, and one or more controllers. The robotic manipulator used for research and analysis in the current research is AUTAREP ED-7220C [18] shown in Fig. 1. The robotic manipulator has five degrees of movement actuated with DC servo motors. A single motor is used to move each joint except the wrist joint where pitch and roll motions are controlled by two motors. The model characterizes an extremely non-linear system since velocities as well as positions of links are coupled dynamically. For feedback from joints, the robotic arm has optical encoders mounted on each joint servo motor axis, which provides information about its position. An adequate motion control algorithm could be accomplished through mathematical modelling by considering the dynamics of the robot manipulator.

Kinematics of a robot gives the relationship between joint angles/translations and the location (position and orientation) of its end-effector [19]. The kinematic model of the manipulator established on 


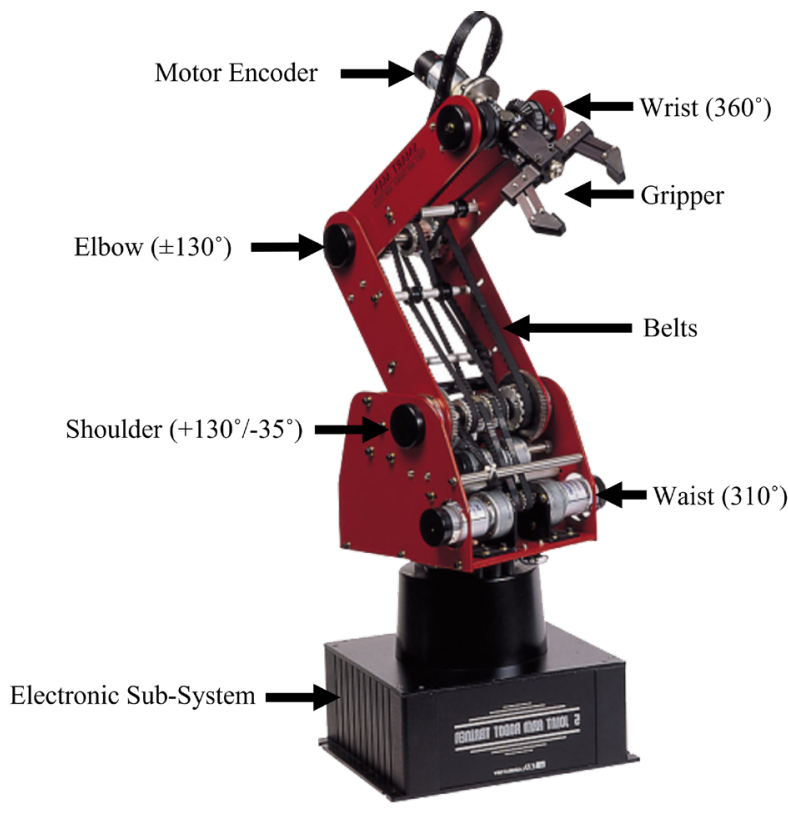

Fig. 1. AUTAREP Manipulator ED-7220C with joints corresponding range of motions

Denavit-Hartenberg (D-H) parameters is reported in [20]. The process of modelling the robot dynamics involves derivation of velocities and inertia matrices, computation of kinetic and potential energies and final formulation of torque equation [21]. Each link of the manipulator is considered as a set of number of elements for which potential and kinetic energies are developed. In the present research work, the Lagrangean approach is used for the formulation of dynamics [22]. Fig. 2 illustrates the kinematic representation of AUTAREP manipulator. In order to function motors, the model should be able to evaluate the joint torques which are system control input [23]. The manipulator's dynamic equation is given by Eq. (1):

$$
\tau_{f}=M\left(q_{i}\right) \ddot{q}_{i}+C_{c}\left(q_{i}, \dot{q}_{i}\right) \dot{q}_{i}+G\left(q_{i}\right)+T_{f}\left(\dot{q}_{i}\right),
$$

where for $n$ joints, $M\left(q_{i}\right) \in R^{n \times n}$ is the mass/inertial matrix, $C_{c}\left(q_{i}\right) \in R^{n \times n}$ represents the coriolis and centripetal forces, $G\left(q_{i}\right) \in R^{n \times 1}$ is the gravitational matrix, $T_{f}\left(\dot{q}_{i}\right) \in R^{n \times 1}$ represents friction torques. The term $\tau_{f} \in R^{n \times 1}$ is the vector of input torques applied to the joints of the robot. Friction is one of the major causes of undesirable effects. Numerous dynamic models for friction have been suggested in literature, including the Dahl model and LuGre model [24], etc.

The dynamic Dahl friction model forms the origin of the LuGre friction model and is an integrated dynamic model of friction. However, it does not

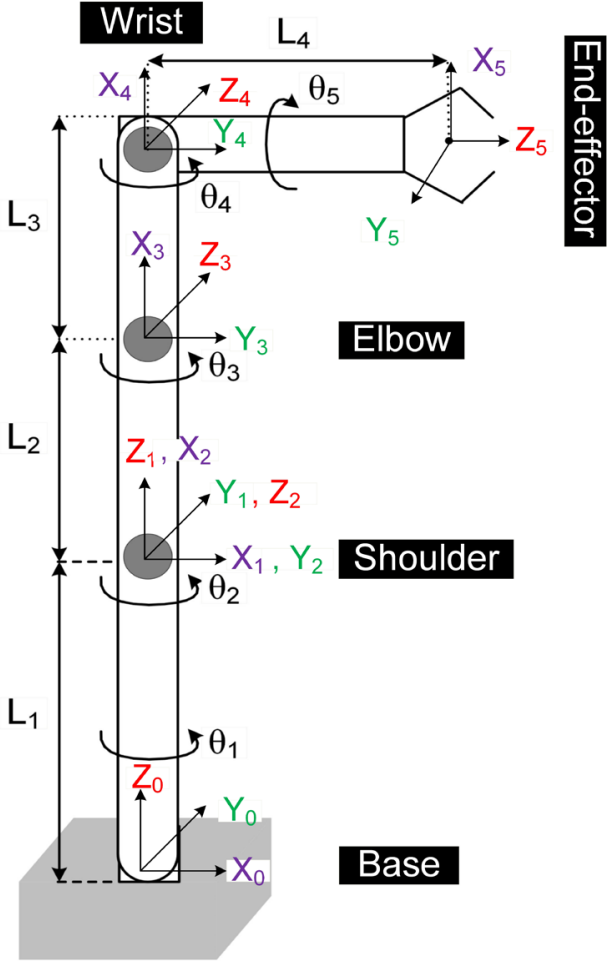

Fig. 2. Kinematic representation of the robotic arm where $\left(L_{1}=385\right.$ $\mathrm{mm}, L_{2}=220 \mathrm{~mm}, L_{3}=220 \mathrm{~mm}, L_{4}=155 \mathrm{~mm}$ )

consider all the non-linear phenomena caused by friction. In the literature, it has been shown that static models cannot capture certain characteristics of true frictional phenomena that are experimentally seen in high friction systems. Therefore, LuGre model of friction is a dynamic friction model related to the bristle interpretation of friction and the average deflection force of elastic springs is used to model friction. The velocity determines the average bristle deflection for a steady state motion. It is lower at low speeds, implying that steady-state deflection decreases with increasing velocity. Rate dependent friction phenomena such as varying break-away force and frictional lag are also included in the model. Therefore, the LuGre model is used here for friction modeling and is given as

$$
T_{f}=\sigma_{0} z+\sigma_{1} \dot{z}+f(v),
$$

where $f(v)=\sigma_{2} v, z$ is internal friction state and the term $T_{f}$ is predicted friction torque.

$$
T_{f}=\sigma_{0} z+\sigma_{1} \dot{z}+\sigma_{2} v .
$$

The dynamics of friction state $z$ can be defined as:

$$
\dot{z}=v-\sigma_{0} \frac{|v|}{g(v)} z
$$


where $g(v)$ is given by:

$$
g(v)=F_{c}+\left(F_{s}-F_{c}\right) \exp ^{-\left(\left|v / v_{s}\right|\right)} .
$$

The LuGre model can illustrate several properties of real friction, for example the limit cycle displacement in stick-slip motion. For steady-state friction measurement the functions $f(v)$ and $g(v)$ can be used. The model has a significant drawback in that, this does not take into account the dwell time effect, which implies that it cannot model variations in friction force when two surfaces are maintained in contact at rest for a set period. The LuGre model is a dynamical system with the following properties: internal state dissipativity, boundedness, $I / O$ dissipativity with constant $\sigma_{1}$ and velocity-dependent $\sigma_{1}(v)$ [25]. Most of these are reasonable characteristics of a model illustrating friction. Parameters of LuGre friction model are obtained from literature [26] and are given in Table 1.

Table 1. Parameters of LuGre friction model

\begin{tabular}{cccc}
\hline Parameter & Value & Unit & Description \\
\hline$\sigma_{0}$ & 2750 & $\mathrm{Nm} / \mathrm{rad}$ & Stiffness coefficient \\
\hline$F_{s}$ & 8.875 & $\mathrm{Nm}$ & Static friction torque \\
\hline$F_{c}$ & 6.975275 & $\mathrm{Nm}$ & Coulomb friction torque \\
\hline$\sigma_{1}$ & 45.2 & $\mathrm{Nm} \cdot \mathrm{s} / \mathrm{rad}$ & Damping coefficient \\
\hline$\sigma_{2}$ & 1.819 & $\mathrm{Nm} \cdot \mathrm{s} / \mathrm{rad}$ & Viscous friction coefficients \\
\hline$v_{s}$ & $6.109 \cdot 10^{-2}$ & $\mathrm{rad} / \mathrm{s}$ & Velocity \\
\hline
\end{tabular}

Let $q_{1}$ is the position vector, $q_{2}$ is the velocity vector and $z_{3}$ is internal friction state. Thus the state-space model of a single joint can be represented by Eq. (6):

$$
\begin{aligned}
& \dot{q}_{1}=q_{2} \\
& \dot{q}_{2}=M^{-1}\left(\tau_{f}-C_{c} q_{2}+G q_{1}+\sigma_{0} z_{3}+\sigma_{2} q_{2}+\sigma_{1} \dot{z}_{3}\right) \\
& \dot{z}_{3}=q_{2}-\sigma_{0} \frac{\left|q_{2}\right|}{g\left(q_{2}\right)} z_{3} .
\end{aligned}
$$

\section{CONTROL DESIGN}

SMC technique permits control of non-linear processes subjected to high model uncertainties and external disturbances [27]. In present research, SMC based law with friction compensation is implemented on AUTAREP manipulator. SMC law is divided into two phases i.e. the sliding phase and the reaching phase [28]. The system trajectories achieve the required sliding surface in the case of reaching phase, defined as:

$$
\dot{q}_{i}=f\left(q_{i}\right)+g\left(q_{i}\right) u+\Delta\left(q_{i}, t\right) .
$$

The vector fields $f\left(q_{i}\right)$ and $g\left(q_{i}\right)$ are the non linear functions representing the system with matched uncertainties $\Delta\left(q_{i}, t\right)$. For the control design, the first step is to define a sliding surface and the whole system states are forced in such a way that the sliding surface converges to zero in a finite time and remains there as long as there is no change in reference input [29]. The control objective in this work is to make sure that the robot should track the predefined trajectory $q_{d i}$. To accomplish this aim, a sliding surface based on error signal for each link is described in Eq. (8):

$$
S_{s i}=C_{s} \dot{e}_{s} i+\lambda_{s i} e_{s i}+I_{s i} \int e_{s i} d t,
$$

where $C_{s}, \lambda_{s i}$ and $I_{s i}$ are positive constants. The tracking function is established for well-defined sliding surface in Eq. (8). Thus, the sliding surface will converge to zero with the applied control effort. This will ensure the tracking error $e_{s i}$ converges to the origin. The control input of SMC law comprises of two parts. The first part is equivalent control law $\left(u_{s e q}\right)$ and it is a continuous term. The second part is discontinuous control law $\left(u_{s d i s}\right)$ with the signum function.

$$
u=u_{\text {seq }}+u_{\text {sdis }} .
$$

The equivalent control input $\left(u_{s e q}\right)$ is acquired through sliding surface by considering $\dot{S}_{s i}=0$ which is obtained after taking the time derivative of Eq. (8):

$$
\dot{S}_{s i}=C_{s} \ddot{e}_{s i}+\lambda_{s i} \dot{e}_{s i}+I_{s i} e_{s i} .
$$

In SMC, the objective is accomplished by setting $\dot{S}_{s i}=0$. Substituting this value in Eq. (10):

$$
0=C_{s} \ddot{e}_{s i}+\lambda_{s i} \dot{e}_{s i}+I_{s i} e_{s i},
$$

where $\dot{e}_{s i}=\dot{q}_{d i}-\dot{q}_{i}$ and $\ddot{e}_{s i}=\ddot{q}_{d i}-\ddot{q}_{i}$ are the first and second time derivatives of error function respectively. Substituting error dynamics, we get:

$$
\begin{gathered}
0=C_{s}\left(\ddot{q}_{d i}-\ddot{q}_{i}\right)+\lambda_{s i}\left(\dot{q}_{d i}-\dot{q}_{i}\right)+I_{s i}\left(q_{d i}-q_{i}\right), \\
\ddot{q}_{i}=\left(C_{s}\right)^{-1}\left[\left(\lambda_{s i}\left(\dot{q}_{d i}-\dot{q}_{i}\right)+I_{s i}\left(q_{d i}-q_{i}\right)\right]+\ddot{q}_{d i} .\right.
\end{gathered}
$$

The equivalent control effort $u_{s e q}$ is chosen as:

$$
\begin{aligned}
u_{s e q}= & M\left(q_{i}\right)\left(C_{s}\right)^{-1}\left[\left(\lambda_{s i}\left(\dot{q}_{d i}-\dot{q}_{i}\right)+I_{s i}\left(q_{d i}-q_{i}\right)\right]\right. \\
& +\ddot{q}_{d}+\left(C_{c}\right)\left(q_{i}, \dot{q}_{i}\right)+G\left(q_{i}\right)+T_{f}\left(\dot{q}_{i}\right) .
\end{aligned}
$$

In order to compensate the dynamic model uncertainties, the discontinuous function $u_{s d i s}$ is defined as given in Eq. (15):

$$
u_{s d i s}=-k_{s i} \operatorname{sign}\left(S_{s i}\right)-\zeta S_{s i},
$$

where $k_{s i}$ and $\zeta$ are positive constants. The equivelant control input $u_{\text {seq }}$ drives the system from initial 
state to sliding surface and ensures that $\dot{S}=0$. However, due to different uncertainties and external disturbances the sliding surface may not converge to zero. Lyapunov stability-based method is used for analysis and control design which guarantees the system stability. For stability analysis, a positive definite Lyapunov energy-function for SMC is chosen as Eq. (16):

$$
V=\frac{1}{2} S_{s i}^{2}
$$

Taking derivative of Eq. (16), we obtain:

$$
\dot{V}=S_{s i} \dot{S}_{s i}
$$

By substituting the value of $\dot{S}_{s i}$ given in Eq. (12) and substituting $u_{\text {seq }}$ as well $u_{\text {sdis }}$ in Eq. (17), we get:

$$
\begin{gathered}
\dot{V}=S_{s i}\left(-k_{s i} \operatorname{sign}\left(S_{s i}\right)-\zeta S_{s i}\right), \\
\dot{V} \leq-k_{s i}\left|S_{s i}\right|-\zeta\left(S_{s i}\right)^{2} .
\end{gathered}
$$

The derivative of Lyapunov function $\dot{V}$, turns out to be negative semi-definite function which is sufficient condition for Lyapunov stability. Therefore, the dynamics of system will converge in finite time and the error will converge to zero for the applied input given in Eq. (20):

$$
\begin{aligned}
& \tau_{f}=M\left(q_{i}\right) C_{s}^{-1}\left[\left(\lambda_{s i}\left(\dot{q}_{d i}-\dot{q}_{i}\right)+I_{s i}\left(q_{d i}-q_{i}\right)\right]\right. \\
& +\ddot{q}_{d i}+C_{c}\left(q_{i}, \dot{q}_{i}\right)+G\left(q_{i}\right)+T_{f}\left(\dot{q}_{i}\right) \\
& -k_{s i g n} S_{s i}-\zeta S_{s i} .
\end{aligned}
$$

\subsection{Experimental Setup}

The proposed control algorithm is also tested on the experimental setup using LabView environment and NI myRIO-1900 hardware. The experimental setup is shown in Fig. 3. The myRIO-1900 is a tool used to implement multiple design concepts with one reconfigurable input/output (I/O) device. It is a portable device that can be used to design and develop various applications in robotics as well in mechatronic systems. It consists of a Xilinx Field Programmable Gate Arrays (FGPA), digital I/O lines and analog inputs as well as analog outputs. It has a built-in accelerometer with distinct features such as Universal asynchronous receiver-transmitter (UART), audio input and output terminals and a pulse width modulator. The myRIO-1900 is a WiFi-enabled edition which allows for speedy integration into remotely control embedded applications. The myRIO-1900 is programmed with LabVIEW using graphical programming language (G-Programming)

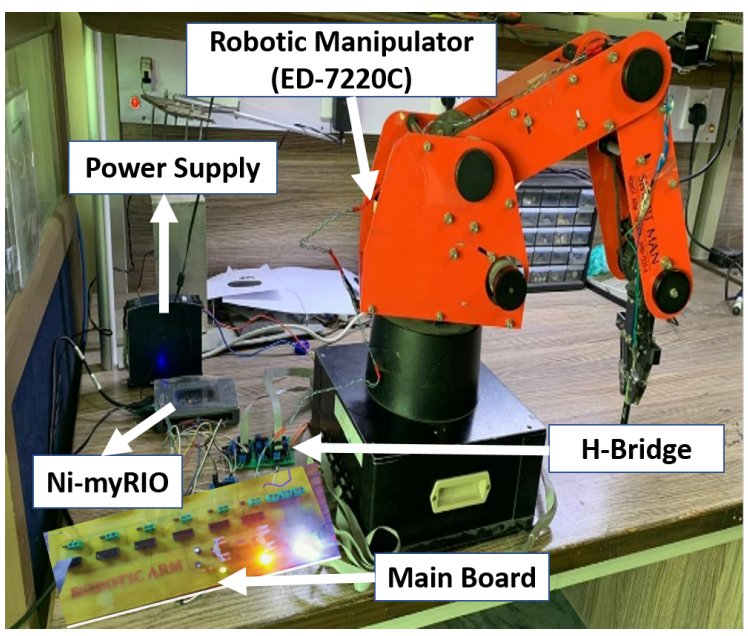

Fig. 3. Hardware setup

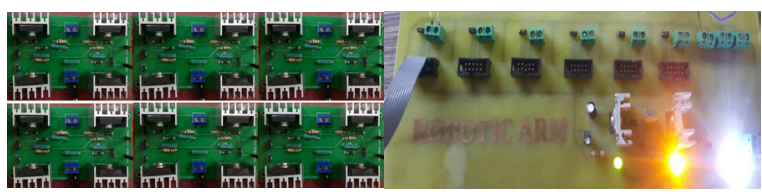

(a) Motor driving board

(b) Main board

Fig. 4. Motors driver board for robotic manipulator

with a high data flow and a building block that can be used for link data acquisition, logical operations, and analysis.

In the proposed solution, digital outputs are used for controlling the actuators that are interfaced through indigenously designed $\mathrm{H}$-bridges by using power transistors TIP147 and TIP142 as shown in Fig. 4a with current rating of five Amperes. The movement of rotary joints in a robot manipulator is controlled by using motor driver circuitry and the Fig. $4 \mathrm{~b}$ presents the main board which connects the robotic manipulator with motor driving board. The desired speed of the motor is accomplished by controlling the voltage via pulse width modulation of the corresponding duty cycle. The actuators are integrated with optical encoders to determine the joint positions and their signals are sent to the myRIO for data processing.

\section{RESULTS AND DISCUSSIONS}

Matlab/Simulink is used for simulation. To validate the model, simulations are conducted using Matlab R2016a installed on a core i5 processor system having 6 GB random access memory. Step response is presented for the elbow joint of the robot manipulator 
as shown in Fig. 5 while sinusoidal response is plotted for the base joint as presented in Fig. 6 .

The desired step input signal of amplitude of $0.1 \mathrm{rad}$ is given to the closed loop system and Fig. 5a shows simulation results for a control law that is designed to track a unit step function with and without friction compensation. Although there is no overshoot in Fig. 5a, but it shows an improvement in settling time in the case of the controller with friction compensation. The controller with friction compensation has settling time of 1 second as compared to 2 second settling time without considering the friction. The results show that the response of ISMC is better for friction taking into account in terms of steady-state error. The Fig. 5b demonstrates the control effort in elbow joint of robotic manipulator. The results clearly indicate that the more control effort is required for controller without friction and control input exhibits an unwanted chattering phenomenon, which can be damaging to the system's mechanical and electrical components. The trajectories of system begin from the sliding surface and the reaching phase is removed with the help of integral term in the sliding surface manifold. However, a discontinuous term of the switching control appears in the resulting joint torque. The chattering impact is the main hurdle in the practical realization of the sliding mode control. An integral term of SMC improves the outcomes by simplifying the higher order derivatives of the system. In the figure, it can be observed from the result that the control effort with friction compensation-based SMC allows the system to track the required trajectory with more precision and accuracy as compared to SMC without considering the friction model. Fig. 5c demonstrates the tracking error signal with and without friction compensation. As figure shows that at time of one second the error signal is zero with friction compensation as compared to 0.15 with out considering friction. The internal state of friction in elbow joint of robotic manipulator is illustrated in $5 \mathrm{~d}$.

In Fig. 6, to test the closed loop tracking performance of the robot manipulator system, the desired differentiable sinusoidal input signal is generated with an amplitude and frequency of 0.1 rad and $0.016 \mathrm{~Hz}$, respectively. The simulation results are generated with and without friction compensation. 6a illustrates the sinusoidal response of base. At some point actual position attains the required trajectory then it follows the desired path for remaining time. In the figure, It can be observed from the results that the control effort with friction compensation-based control allows the system to track the required trajectory with more precision and accuracy as compared to SMC without considering the friction model. Fig. $6 \mathrm{~b}$ illustrates the control effect in the form of applied torque to the base. The control effort is calculated using the control law defined in Eq. (19). The SMC based law reduces the chattering effect, when the dynamics of the system are weak against the uncertainties. Fig. $6 \mathrm{c}$ shows the error signal between actual and desired positions of the base. These results show that SMC with friction compensation demonstrates better performance with nearly zero error signal compared to SMC without friction compensation. In the figure, it can be observed that without friction compensation error signal has greater amplitude of error in comparison to friction compensation error signal. Fig. 6d shows the internal state of LuGre friction model in base joint of the AUTAREP robot manipulator.

Figs. $7 \mathrm{a}$ and $\mathrm{b}$ present the experimental results of joints of the robot manipulator. Fig. 7a demonstrates the step input response for base joint of the robot manipulator and shows that the joint reaches the desired position in $0.6 \mathrm{sec}$ with overshoot. It can be seen that both transient and steady-state parameters are within acceptable limits. Sinusoidal response of base joint is also shown in Fig. 7b. The results demonstrate the well-known chattering phenomenon. This behavior of the system is undesirable and it may cause heat and energy dissipation and wear and tear of various components in the system. The chattering phenomenon can be reduced by implementing other variants of SMC such as higher order SMC.

The proposed ISMC technique and the adaptive sliding mode control (ASMC) methodology implemented in [30] are compared in Fig. 7c. By employing SMC's reaching condition, these trajectories approach zero and provide asymptotic stability to the system. Fig. 7c demonstrates the tracking behavior between both the current and desired positions which does not exceed $1.5 \mathrm{~s}$ for both techniques. The ISMC method has settling time of $1.25 \mathrm{~s}$ with friction compensation in comparison to $1.45 \mathrm{~s}$ for control law proposed in [30]. It has rise time of 214.9 milli second with overshoot of $0.792 \%$ in comparison to ASMC technique having 270.63 milli-second rise time and overshoot of 0.658 $\%$. The passivity based adaptive control of a serial robotic manipulator is implemented in [31] using joint frictions depending upon temperature. The position tracking of said technique along with the method implemented in this paper is shown in Fig. 7d. The position tracking in ISMC has better convergence performance and asymptotic convergence in comparison to method proposed in [31]. The 


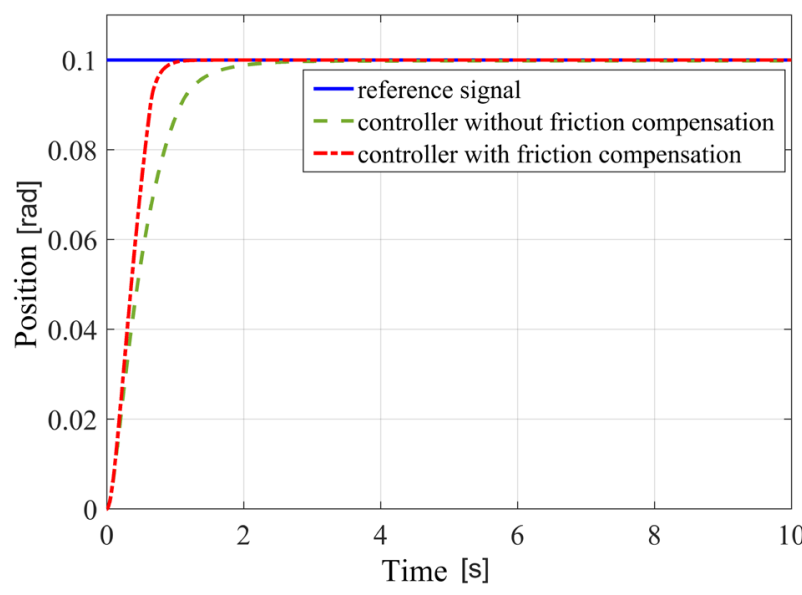

(a) Angular position of elbow joint

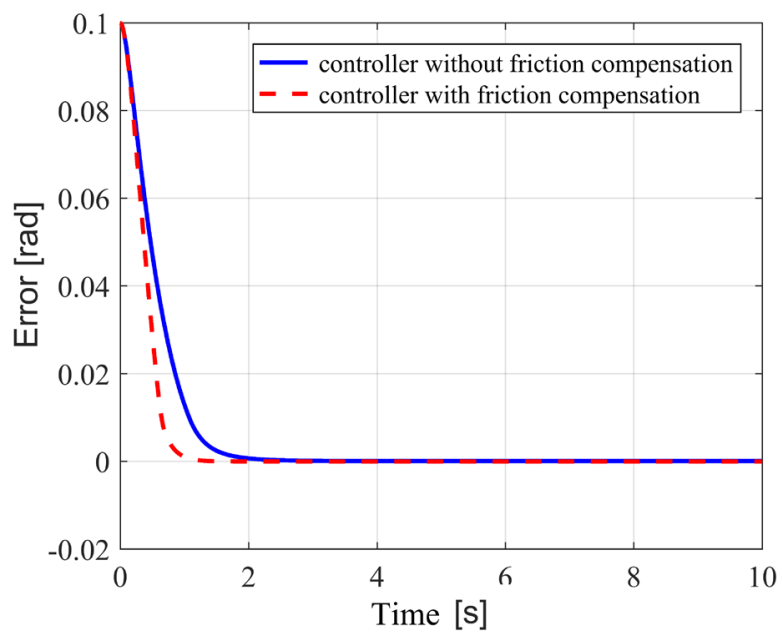

(c) Error signal

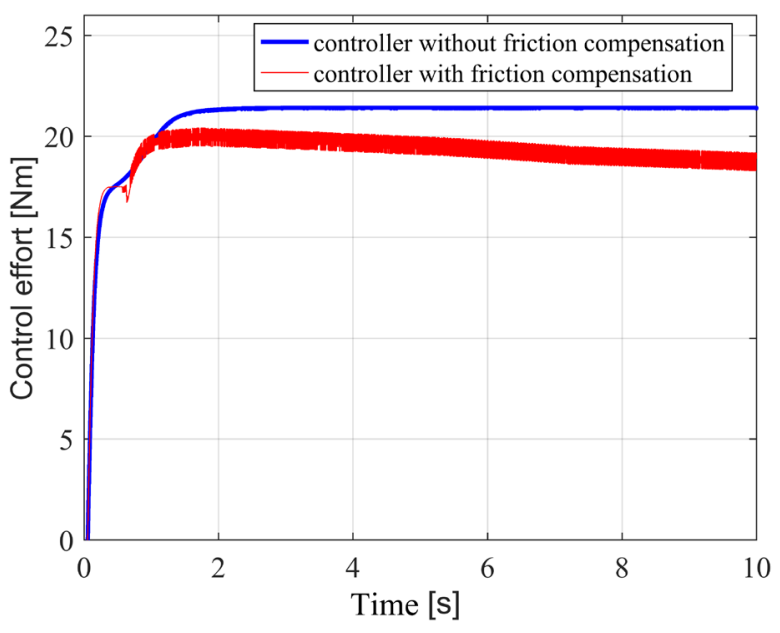

(b) Control effort

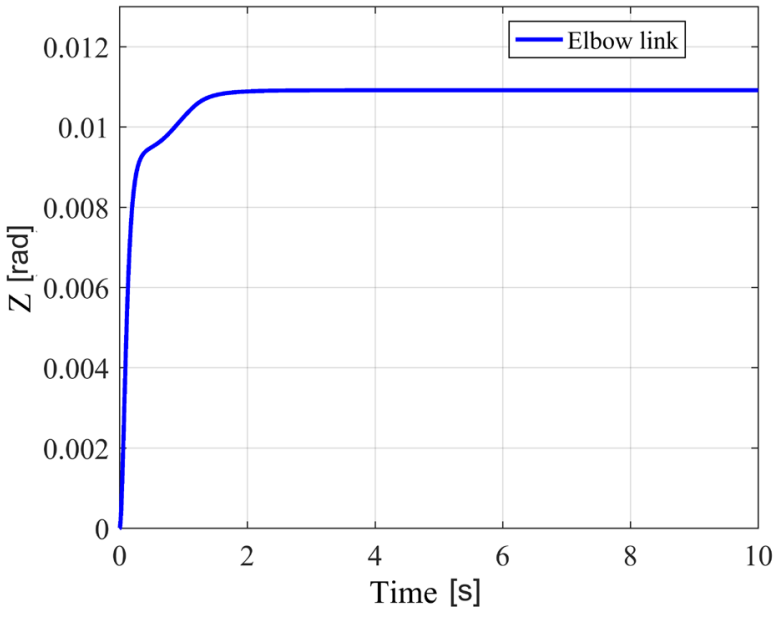

(d) Friction state $z$

Fig. 5. Step response obtained by the elbow joint of the robotic manipulator

negative aspect in the proposed technique ISMC with friction compensation is that the temperature effect of joints are not considered as well high control gains and high control efforts related to chattering issues. As robotic manipulators are often used in various applications where the joints get warmer due to the friction after the manipulator operates for some time. They may also be used when the temperature varies from very low to very hot degrees. The temperature effects must therefore be considered.

\section{CONCLUSIONS}

In this research work, a sliding mode control with an integral term is proposed for the desired trajectory tracking and robotic manipulator is modeled using dynamic LuGre friction model. The effectiveness of the proposed ISMC technique is initially validated in Matlab and simulation findings are shown to illustrate the effectiveness of the designed robust controller with and without considering the friction. The proposed control scheme is then evaluated by comparing with the other sliding mode control techniques. The ISMC technique performs superior in terms of system control efforts and transient parameters involving percentage overshoot, rise time and settling time etc. have been witnessed to be within certain bounds as anticipated. The proposed control law is also being tested on the custom developed experimental test bench using LabVIEW and NI-myRIO. 


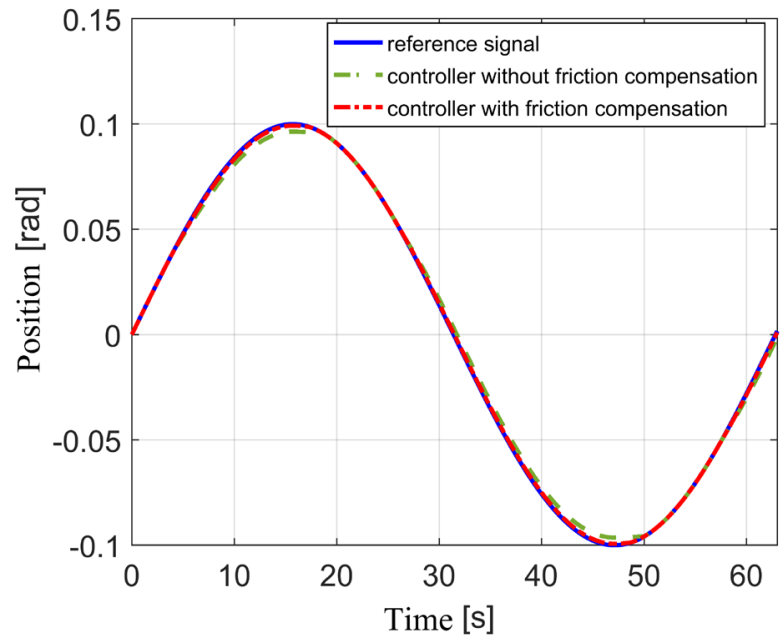

(a) Angular position of base joint

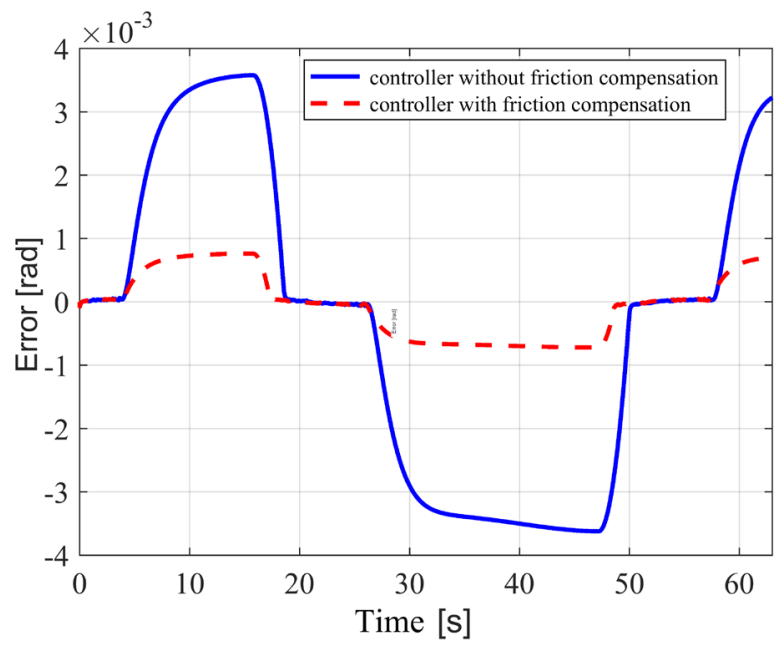

(c) Error signal

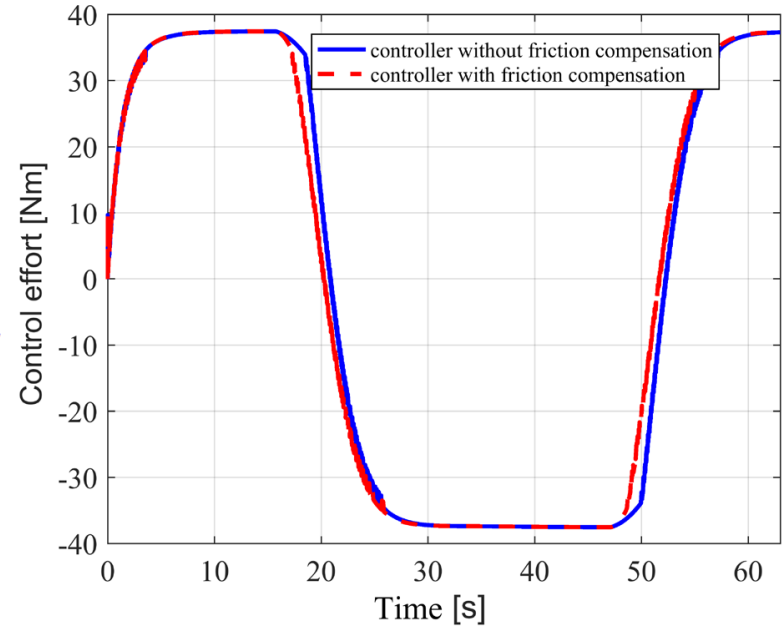

(b) Control effort

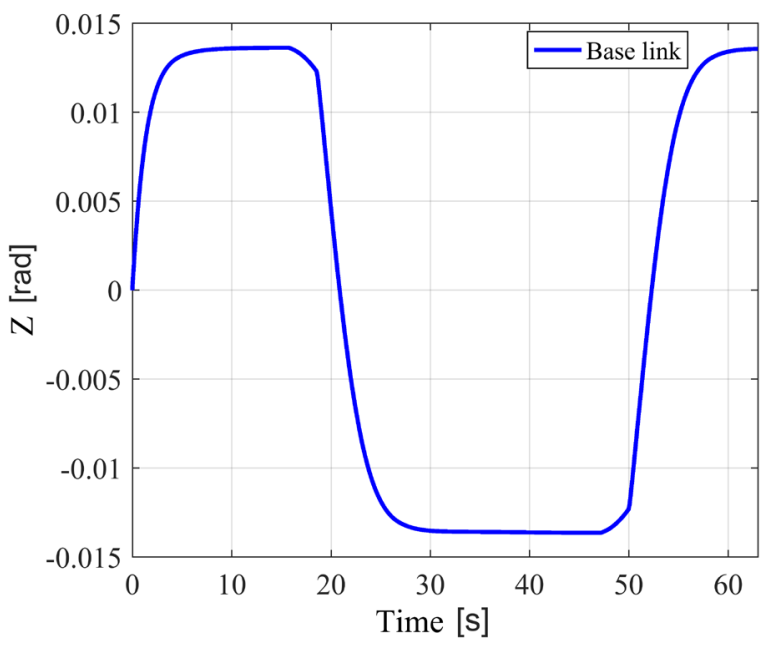

(d) Friction state $z$

Fig. 6. Sinusoidal input signal response obtained by the base joint of the robotic manipulator

\section{REFERENCES}

[1] Iqbal, J., Islam, R.U., Abbas, S.Z., Khan, A.A., Ajwad, S.A. (2016). Automating industrial tasks through mechatronic systems-A review of robotics in industrial perspective. Technical Gazette - Tehnički vjesnik, vol. 23, no. 3, p. 917-924, DOI:10.17559/TV-20140724220401.

[2] Mei, J., Zang, J., Ding, Y., Xie, S., Zhang, X. (2017). Rapid and automatic zero-offset calibration of a 2-DOF parallel robot based on a new measuring mechanism. Strojniški vestnik - Journal of Mechanical Engineering, vol. 63, no. 12, p. 715-724, DOI:10.5545/sv-jme.2017.4529.

[3] Ajwad, S.A., lqbal, J., Khan, A.A., Mehmood, A. (2015). Disturbance-observer-based robust control of a serial-link robotic manipulator using SMC and PBC techniques. Studies in Informatics and Control, vol. 24, no. 4, p. 401-408, DOI:10.24846/v24i4y201504.

[4] Liu, H., Tian, X., Wang, G., Zhang, T. (2016). Finite-Time $H_{\infty}$ Control for high-precision tracking in robotic manipulators using backstepping control. IEEE Transactions on Industrial Electronics, vol. 63, no. 9, p. 5501-5513, DOI:10.1109/TIE.2016.2583998.

[5] Erkaya, S. (2018). Effects of joint clearance on the motion accuracy of robotic manipulators. Strojniški vestnik - Journal of Mechanical Engineering, vol. 64, no. 2, p. 82-94, DOI:10.5545/sv-jme.2017.4534.

[6] Podgornik, B., Hogmark, S., Sandberg, O. (2004). Wear and friction properties of coatings for forming tools. Strojniški vestnik - Journal of Mechanical Engineering, vol. 50, no. 3, p. 156.

[7] Linderoth, M., Stolt, A., Robertsson, A., Johansson, R. (2013). Robotic force estimation using motor torques and modeling of low velocity friction disturbances. 


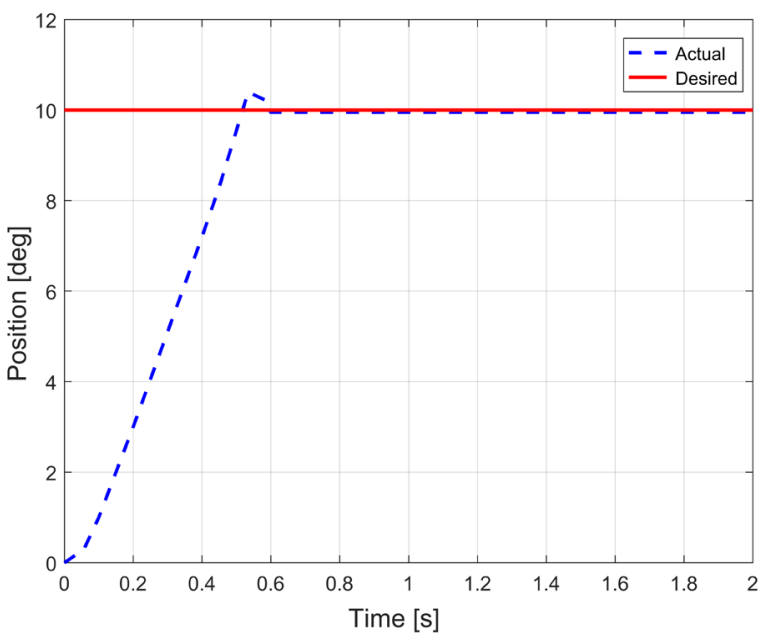

(a) Experimental results for a step input

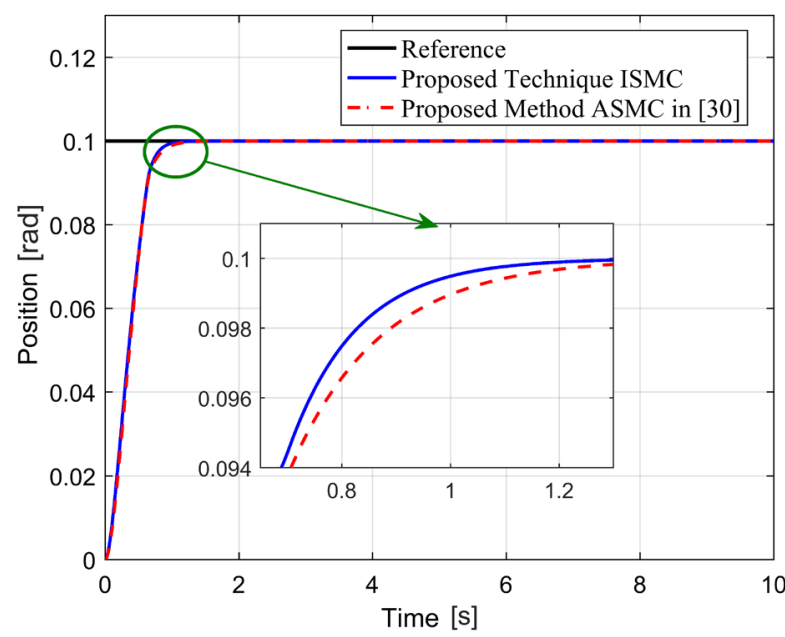

(c) Comparison of results with ASMC method in [30]

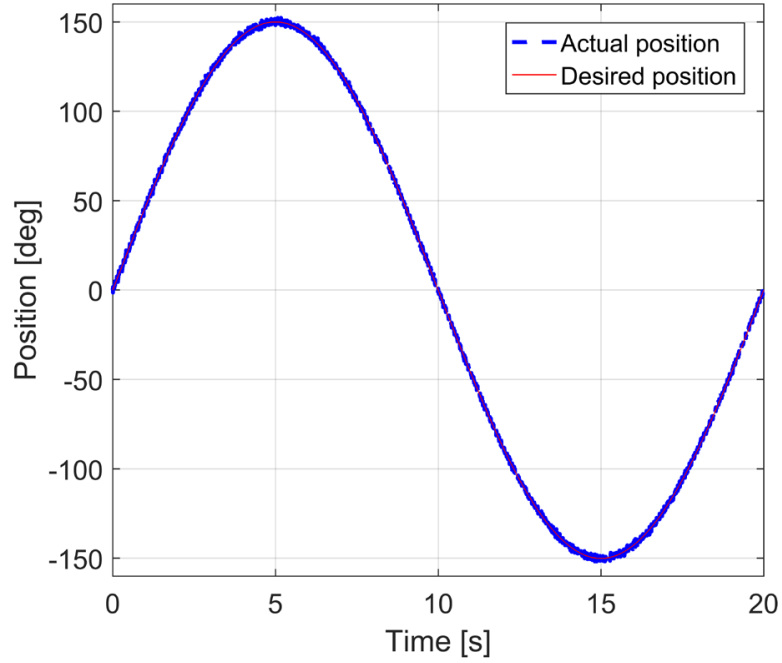

(b) Experimental results for a sinusoidal input

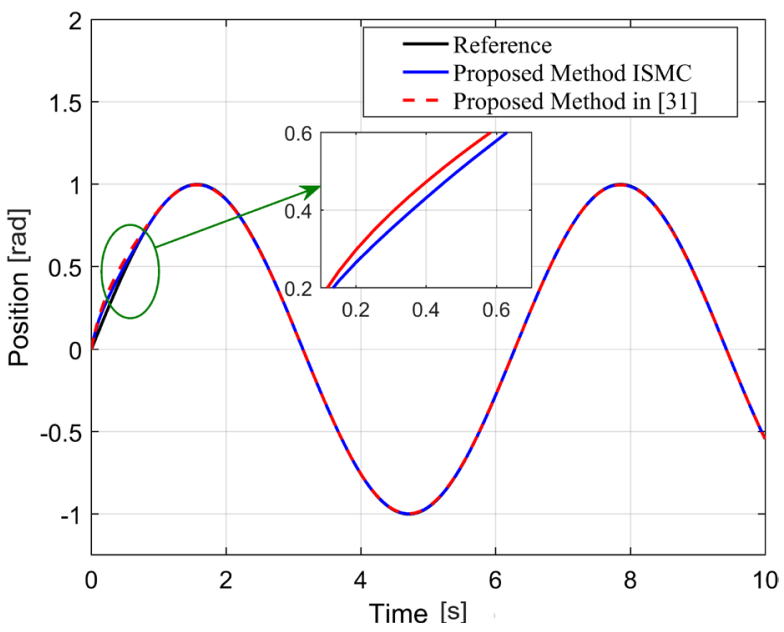

(d) Comparison of results with control method in [31]

Fig. 7. Experimental results and proposed technique comparisons

In 2013 IEEE/RSJ International Conference on Intelligent Robots and Systems, p. 3550-3556, DOI:10.1109/IROS.2013.6696862.

[8] Correia, M.D., Gustavo, A., Conceição, S. (2012). Modeling of a three wheeled omnidirectional robot including friction models. IFAC Proceedings Volumes, vol. 45, no. 22, p. 7-12, DOI:10.3182/20120905-3-HR-2030.00002.

[9] Zhang, D., Niu, Y., Sun, L., Tomizuka, M. (2019). A position-based friction error model and its application to parameter identification. IEEE Access, vol. 7, p. 7759-7767, DOI:10.1109/ACCESS.2018.2890669.

[10] Segalman, D.J. (2006). Modelling joint friction in structural dynamics. Structural Control and Health Monitoring, vol. 13, no. 1, p. 430-453, DOI:10.1002/stc.119.

[11] Ma, W., Deng, W., Yao, J. (2018). Continuous integral robust control of electro-hydraulic systems with modeling uncertainties. IEEE Access, vol. 6, p. 46146-46156, DOI:10.1109/ACCESS.2018.2866270.

[12] Erenturk, K. (2008). Nonlinear two-mass system control with sliding-mode and optimised proportional-integral derivative controller combined with a grey estimator. IET Control Theory \& Applications, vol. 2, no. 7, p. 635-642, DOI:10.1049/iet-cta:20070330.

[13] Ajwad, S.A., Iqbal, J., Ullah, M.I., Mehmood, A. (2015). A systematic review of current and emergent manipulator control approaches. Frontiers of Mechanical Engineering, vol. 10, no. 2, p. 198-210, DOI:10.1007/s11465-015-0335-0.

[14] Hacioglu, Y., Yagiz, N. (2019). Fuzzy robust backstepping with estimation for the control of a robot manipulator. Transactions of the Institute of Measurement and Control, vol. 41, no. 10, p. 2816-2825, 


\section{DOI:10.1177/0142331218814290.}

[15] Li, D.Y., Zheng, J., Hao, W.R. J., Wang, S.K., Shen, W. (2017). Adaptive robust controller for electric cylinder with fast parameter estimation based on modified lugre model. $36^{\text {th }}$ Chinese Control Conference (CCC), p. 3315-3320, DOI:10.23919/ChiCC.2017.8027870.

[16] Wu, Z. (2019). Adaptive block compensation trajectory tracking control based on LuGre friction model. International Journal of Advanced Robotic Systems, vol. 16, no. 5, DOI:10.1177/1729881419873212.

[17] Lee, J., Chang, P.H., Jin, M. (2017). Adaptive integral sliding mode control with time-delay estimation for robot manipulators. IEEE Transactions on Industrial Electronics, vol. 64, no. 8, p. 6796-6804, DOI:10.1109/TIE.2017.2698416.

[18] Manzoor, S., Islam, R.U., Khalid, A., Samad, A., Iqbal, J. (2014). An open-source multi-DOF articulated robotic educational platform for autonomous object manipulation. Robotics and Computer-Integrated Manufacturing, vol. 30, no. 3, p. 351-362, DOI:10.1016/j.rcim.2013.11.003.

[19] Serrezuela, R.R., Chavarro, A.F.C., Cardozo, M.A.T., Toquica, A.L., Martinez, L.F.O. (2017). Kinematic modelling of a robotic arm manipulator using Matlab. ARPN Journal of Engineering and Applied Sciences, vol. 12, no. 7, p. 2037-2045.

[20] Ajwad, S.A., Iqbal, J., Islam, R.U., Alsheikhy, A., Almeshal, A., Mehmood, A. (2018). Optimal and robust control of multi DOF robotic manipulator: Design and hardware realization. Cybernetics and Systems, vol. 49, no. 1, p. 77-93, DOI:10.1080/01969722.2017.1412905.

[21] Han, S., Wang, H., Tian, Y. (2017). Integral backstepping based computed torque control for a 6 DOF arm robot. $29^{\text {th }}$ Chinese Control And Decision Conference (CCDC), p. 4055-4060, DOI:10.1109/CCDC.2017.7979210.

[22] Siciliano, B., Sciavicco, L., Villani, L., Oriolo, G. (2010). Robotics: Modelling, Planning and Control. Springer Science \& Business Media, London, DOI:10.1007/978-1-84628-642-1.

[23] Khan, O., Pervaiz, M., Ahmad, E., lqbal, J. (2017). On the derivation of novel model and sophisticated control of flexible joint manipulator. Revue Roumaine des Sciences Techniques-Serie Electrotechnique et Energetique, vol. 62, no. 1, p. 103-108.

[24] Yao, J., Deng, W., Jiao, Z. (2015). Adaptive control of hydraulic actuators with LuGre model-based friction compensation. IEEE Transactions on Industrial Electronics, vol. 62, no. 10, p. 6469-6477, DOI:10.1109/TIE.2015.2423660.

[25] Astrom, K.J. (2008). Revisiting the LuGre friction model. IEEE control systems Magazine, vol. 28, no. 6, p. 101-114, DOI:10.1109/MCS.2008.929425.

[26] Wang, X., Wang, S. (2015). Output torque tracking control of direct-drive rotary torque motor with dynamic friction compensation. Journal of the Franklin Institute, vol. 352, no. 11, p. 5361-5379, DOI:10.1016/j.jfranklin.2015.08.021.

[27] Zhang, L., Liu, L., Wang, Z., Xia, Y. (2018). Continuous finite-time control for uncertain robot manipulators with integral sliding mode. IET Control
Theory \& Applications, vol. 12, no. 11, p. 1621-1627, DOI:10.1049/iet-cta.2017.1361.

[28] Alam, W., Mehmood, A., Ali, K., Javaid, U., Alharbi, S., Iqbal, J. (2018). Nonlinear control of a flexible joint robotic manipulator with experimental validation. Strojniški vestnik - Journal of Mechanical Engineering, vol. 64, no. 1, p. 47-55. DOI:10.5545/sv-jme.2017.4786.

[29] Dumlu, A., Erentürk, K., Kaleli, A., Ayten, K.K. (2017). A comparative study of two model-based control techniques for the industrial manipulator. Robotica, vol. 35, no. 10, p. 2036-2055, DOI:10.5545/sv-jme.2017.4786.

[30] Tu'ma, D.H., Hamoudi, A.K. (2020). Performance of 2-link robot by utilizing adaptive sliding mode controller. Journal of Engineering, vol. 26, no. 12, p. 44-65, DOI:10.31026/j.eng.2020.12.03.

[31] Azizi, Y., Yazdizadeh, A. (2019). Passivity-based adaptive control of a 2-DOF serial robot manipulator with temperature dependent joint frictions. International Journal of Adaptive Control and Signal Processing, vol. 33, no. 3, p. 512-526, DOI:10.1002/acs.2968. 